\title{
Construction of Short-Term Memory Training Model in Consecutive Interpretation*
}

\author{
Jixin Huang \\ School of Foreign Languages, Zunyi Medical University, Zunyi, Guizhou, 563000, China
}

\begin{abstract}
With the deepening of the reform and opening up policy, China is moving towards the world dramatically, and the importance of interpretation is becoming increasingly prominent. Based on the theory of memory in interpretation and the theory of discourse type in interpretation, this paper aims to demonstrate the fit between discourse type and memory, and analyze the effectiveness of the training model through empirical research. In the experiment, students of Translation Class 2018 (reference class) and students of Translation Class 2019 (experimental class) were selected as the research objects, and a six week teaching experiment was carried out. Through the analysis of students' data, questionnaires and interviews, it can be found that the application of the theory of discourse type in interpretation to the training of short-term memory in interpreting can improve the logic and integrity of information transmission, so this teaching model is effective and feasible. The purpose of this study is to construct a training model of short-term memory in consecutive interpretation teaching with the help of the theory of discourse type, so that students can experience the joy of progress in the process of practice, monitoring and reflection, which will greatly mobilize students' subjective initiative in learning, stimulate students' innovative consciousness and cultivate students' innovative ability.
\end{abstract}

Index Terms - short-term memory, training model, discourse type, consecutive interpretation

\section{INTRODUCTION}

According to the Teaching Requirements for Undergraduate Translation Major, and the Teaching Guide for Undergraduate Translation Major, the interpretation course is listed as a compulsory course, emphasizing the "skill" in the interpretation course, that is, to enable students to master the basic theory of interpretation and the skills of consecutive interpretation of special topics by teaching the basic theory and background knowledge of interpretation and training basic skills of interpretation. In order to help students interpret Chinese and English accurately and fluently, they should learn the methods of memory, gist retelling and interpreting, notes taking, public speaking skills and so on. Memory training plays an important role in interpreting teaching. There are many factors which may exert great pressure on interpreters, like the "immediacy" of interpretation, and the criteria "accuracy, smoothness and quickness" in interpretation quality assessment $(\mathrm{Li}, 1999)$. Therefore, to deepen the research of short-term memory training in consecutive interpretation can help interpreting learners improve the efficiency of memory in interpreting and the overall quality of interpretation.

\section{LITERATURE REVIEW}

\section{A. Main Works}

At present, most of the interpreting textbooks focus on skills training, containing chapters or units of memory in interpreting. For example, in the Second Edition of Basics of Interpreting Skills, a series of undergraduate textbooks for translation majors edited by Deng Yi and Liu Ying (2016), Unit 2 introduces memory information and auxiliary memory. The fourth and fifth units of the National Excellent Textbook A Coursebook of Interpreting Between English and Chinese edited by Ren Wen (2011) explain the memory mechanism and training methods. Basics of Interpreting Skills edited by Su Wei and Deng Yi (2009) lists memory information as a unit between getting the message through listening and information expressing. A Foundation Coursebook of Interpreting, a textbook for master's degree in translation, edited by Zhong Weihe and Wang Binhua (2009), also tells the basic principles of memory in interpreting in Unit 6. Lei Tianfang and Chen Jing (2006) set up the units of "difficulties in memory" and "improving memory efficiency" in the first few lessons of Challenging Interpreting: A Coursebook of Interpreting Skills.

\section{B. Main Papers}

Deng Lin (2019) in The Study of Memory Mechanism in Consecutive Interpretation, summarizes the main factors that affect the memory effect of translators from the analysis of memory process and mode, and concludes that the interpreter should grasp the overall structure and meaning of the segment. Wu Cai (2017) in On the Strategies to Improve Short-term Memory in Consecutive Interpretation, proposes five strategies to improve short-term memory from

*Fund information: This paper is funded by School of Foreign Languages, Zunyi Medical University (2020w3)" 
its characteristics in the process of consecutive interpretation: extracting key information, memory chunks, image memory, taking notes and retelling.

\section{Main Views}

Short-term memory is the core in information processing and plays a leading role in memory in interpreting. It is compared to the "central processing unit" of a computer. Some people also call it a temporary "processing field" or "working space" for brain thinking activities. The information processing ability of short-term memory has been the focus of academic fields. In Miller's (1956) experiment, the subjects were asked to retell a random number table of 3 to 12 digits. It was found that after the information was presented at one time, the maximum number that the subjects could recall was generally $7 \pm 2$ digits. However, the information breadth of $7 \pm 2$ can be expanded. According to Miller's chunk principle, chunk can combine several small units into large units for information processing. "Chunking" actually refers to the method of information processing. Baddeley (2000) also found the phenomenon of "capacity expansion". He proposed the concept of episodic buffer, which means that information from different sources can be integrated together. The "integration" here is also a "chunk". Bao Xiaoying (2005) further believes that this expansion can be reflected in the expansion of memory units, because $7 \pm 2$ can be $7 \pm 2$ syllables, $7 \pm 2$ words, $7 \pm 2$ phrases, or $7 \pm 2$ short sentences.

In the neuropsychological process model of interpretation constructed by Liu Shaolong and Zhong Weihe (2008), long-term memory is characterized by multiple information network systems (including sensory network system, language network system, knowledge network system, etc.), which provides the necessary retrieval (or access) channels and information resources for speech information processing; Working memory (short-term memory) is the "processing field" of speech information in the "memory system", which undertakes the selection, processing and access of information. Li Fangqin (2004) proposed the outline memory strategy and reasoning memory strategy, which grasped the information level of the original text, combined with logical analysis and reasoning, and increased the capacity of short-term memory. Zhong Weihe (2003) classified the types of memory in interpretation as follows: a. speech coding memory, which is memorized by voice; $b$. visual coding memory stores information in the form of image rather than sound; c. semantic decoding memory is mainly applied to abstract information. Bao Gang (1998) pointed out that "In the practice of interpretation, the instantaneous memory is related to the listening and understanding of the source language. The long-term memory is related to the interpreter's preparation before interpretation, while the short-term memory is related to the interpreter's storage of information such as the content and key words of the source language".

\section{Discourse Types in Interpretation}

Jones (2000) divided discourse into the following types and gave suggestions to interpreters: a. Argumentation: pay special attention to the logic between the original views, and to the structure in understanding and interpreting output, so as to facilitate the audience's understanding; $b$. Narration: it is suggested that special attention should be paid to time, date and tense of verbs; c. Description: the interpreter is advised to concentrate on the most important information; $d$. Strongly debating type: not only guarantee faithfulness, but also convey the gist of original intention and the intensity of emotion; e. The type with more structure than content: it is more important to grasp the essence of the original than the details. Jones's classification is of great help to interpreters. His suggestions can take into account the "key points" understood by the interpreter and the "acceptability" of the interpreter's output from a practical point of view.

According to the previous studies on memory training in interpretation, it is not difficult to find that most of the researches on memory training in interpretation are theoretical, but there is no empirical research on interpretation training. In consecutive interpretation, the research on the construction of short-term memory training model based on the theory of discourse type in interpretation has certain theoretical innovation significance, reflects the advantages of multidisciplinary combination, helps to enhance the sustainability of interpretation research, enriches the theoretical support and method guidance in the whole process of interpretation teaching, and promotes the deepening of interpretation research and interpretation teaching. It forms a closed loop of interpretation theory, teaching and practice.

\section{The Current Situation of Self-Evaluation of Short-Term Memory Learning in Translation Major of ZUNYI MEDICAL UNIVERSITY}

Knowing the current situation of self-evaluation of short-term memory learning is conducive to the development of the experiment. For this reason, "Questionnaire on Memory in Interpretation" is designed for students majoring in translation in Zunyi Medical University in recent five years on Wenjuanxing Website (https://www.wjx.cn). 80 valid questionnaires were collected. Combined with the questionnaire survey, two prominent problems can be found, as shown in Table 1: 
TABLE 1

QUESTIONNAIRE ON MEMORY IN INTERPRETATION (TwO PROMINENT PROBLEMS)

\begin{tabular}{|l|l|l|}
\hline Questions & Choices & Percentage \\
\hline \multirow{3}{*}{$\begin{array}{l}\text { What do you know about } \\
\text { memory in interpretation? }\end{array}$} & Definition & $37 . \%$ \\
\cline { 2 - 3 } & Status and role & $31.25 \%$ \\
\cline { 2 - 3 } & Related works & $11.25 \%$ \\
\cline { 2 - 3 } & Long term memory and short-term memory & $86.25 \%$ \\
\cline { 2 - 3 } & Working memory & $26.25 \%$ \\
\hline $\begin{array}{l}\text { According to your listening } \\
\text { practice, which of the } \\
\text { following situations do you } \\
\text { prefer to memorize? }\end{array}$ & $\begin{array}{l}\text { Memorize just a few words, but the relationship is messy and } \\
\text { fuzzy, and the utilization rate is low }\end{array}$ & $65 \%$ \\
\cline { 2 - 3 } & $\begin{array}{l}\text { Memorize just a few words, but the relationship is clear and the } \\
\text { utilization rate is high }\end{array}$ & $17.5 \%$ \\
\cline { 2 - 3 } & $\begin{array}{l}\text { Memorize a lot of words, but the relationship is messy and } \\
\text { fuzzy, and the utilization rate is low }\end{array}$ & $13.75 \%$ \\
\cline { 2 - 3 } & $\begin{array}{l}\text { Memorize a lot of words, but the relationship is clear and the } \\
\text { utilization rate is high }\end{array}$ & $3.75 \%$ \\
\hline
\end{tabular}

As is shown in Table 1, in terms of the first question, most students only know about long-term memory and short-term memory $(86.25 \%)$, but little know about working memory in interpretation $(26.25 \%)$. Therefore, in the selection of teaching contents, introducing the background information of interpretation memory (definition, status, role, etc.) and the relevant theories of interpretation memory should be the first priority. As for the second question, in listening and memorizing information, $65 \%$ of the students can only record a few words, but the logic is messy, and the utilization rate is low. Therefore, interpreting discourse theory should be introduced into class. The combination of discourse theory in interpreting and memory model can help students classify the discourse and integrate the information they hear, and then memorize and output them according to appropriate memory methods.

\section{Construction of Short-Term Memory Training Model From the PERSPECTIVE OF Discourse TheORY IN INTERPRETING}

Based on the discourse theory in interpreting as well as the various discourse types, it's better to choose some specific materials for interpreting practice.

\section{A. The Practice of Image Memory in Narrative and Descriptive Discourse}

\section{Mind Drawing for Static Image or Information}

E.g.1 In the past, from Nanjing to Hangzhou, you should take the train to the East, bypass Suzhou and Shanghai, and then go south to Hangzhou via Jiaxing. In 2013, after the completion and opening of the Nanjing-Hangzhou Expressway, you do not have to take such a zigzag road to the East from Nanjing, but directly to the south, through Taihu Lake to Hangzhou, which is more than 200 kilometers shorter than before.

The most effective way to memorize this passage is to process the original text into a map and string the cities listed in the original text with railway lines. In this way, the locations of the cities can be clearly seen at a glance, and the efficiency of memory will be greatly improved. The graphic example is as follows:

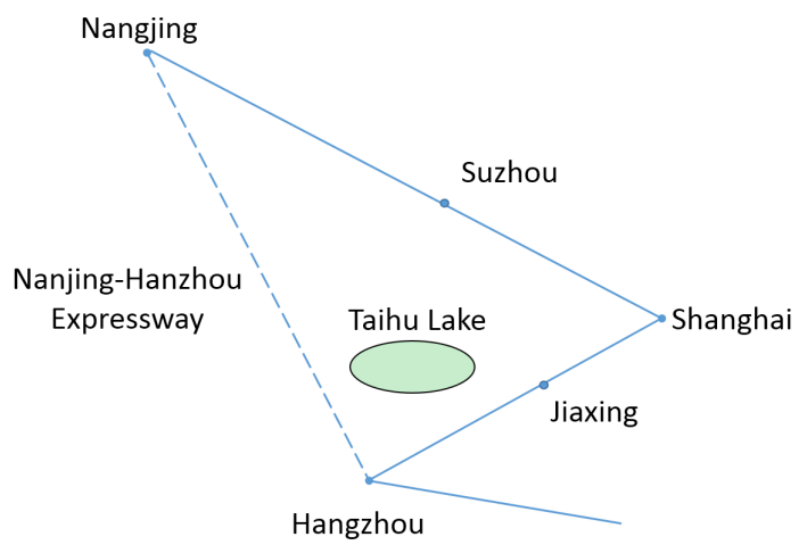

\section{Film Projection for Dynamic Image or Information}

E.g.2 Water breathing exercise: stand in the water, hands forward, palm down, head and upper body with movement of up and down. Exhale in the water, and inhale out of the water. Practice over and over again; then breathe with the stroke of hands. When the hands are floating on the water, the head will enter the water and exhale. When the hands are pulling down 45 degrees, the head will naturally come out of the water and inhale.

When memorizing the above information, you may imagine yourself breathing in the water, and follow the steps of 
the original text step by step, just like the pictures in a movie.

\section{Mind Drawing Plus Fingers Counting for Exposition with Procedures}

E.g.3 Kung Pao Chicken: remove the bone from the washed chicken drumsticks, cut into diced meat, add egg whites, cooking wine, salt, sugar, starch and oil into the diced chicken, mix well, and let stand for 15 to 20 minutes to marinate the diced chicken; Pour the soup, cooking wine, soy sauce and sugar into the bowl, stir evenly to make the sauce and set aside, stir fry the diced chicken and set aside; Pour the oil into the hot pan, add the dried pepper and scallion, stir fry until fragrant, add the bean paste and mashed garlic, stir fry until fragrant, and then pour the sauce in, add water and starch; Then pour in the diced chicken and stir fry until the sauce completely covers the diced chicken; Add vinegar, peanuts and sesame oil and stir fry evenly. Then remove from the pan.

Students can remember what they need to do and the food materials involved in each step with the method of image memory, and record how many steps are needed to make Kung Pao Chicken with the method of finger breaking.

\section{B. The Practice of Logical Memory in Argumentative Discourse}

\section{Gist Extracting and Summarizing}

E.g. 4 In the United States, the last Thursday in April of each year is called "Take Your Children to Work Day". On this day, parents can take their children to the work place and let them learn about their work. The attraction of this kind of activity is that "Take Your Children to Work Day" belongs to the public welfare activities, and the company can get the government's tax preference at the end of the year, so the company's cost is low. More importantly, this kind of activity not only promotes the communication between children and their parents, provides reference for young people to choose their future career, but also helps the company's departments and employees at all levels to understand each other, so as to enhance the cohesion of the enterprise.

When students practice the logical memory of this passage, they can extract the gist according to the logical relationship of "event-what-why", that is, first memorize the event "Take Your Children to Work Day", then what is "Take Your Children to Work Day", and finally memorize why to implement "Take Your Children to Work Day".

\section{Information Layered}

E.g. 5 Doctors also warned that people should pay attention to correct the wrong habits of drinking tea and walking after meals. If you drink tea immediately after meals, tea will dilute gastric juice, affect the normal digestion of food in the stomach. Tannic acid contained in tea can also promote the coagulation of substances in the stomach and affect the absorption of protein, thus increasing the burden on the stomach. In this regard, the doctor suggested that people should not drink tea within one hour after a meal, and should drink tea when the food in the stomach is almost digested after a meal, which will not have a great impact on the digestive function and material coagulation. In addition, it's also unscientific to say, "If you walk a hundred steps after a meal, you will live to ninety-nine." People's stomach is in a state of filling after meals, even very slight movement will make the stomach vibrate, thus increasing the gastrointestinal burden and affecting the digestive function. In this regard, the doctor suggested that it is more appropriate to take a 30-minute rest after meals and wait for the food in the stomach to be properly digested before moving again, so as not to have too much impact on the digestive system. "

This passage introduces two kinds of wrong habits after meals. When students memorize them, they can divide the information into two levels "bad habit1 - what (tea after meals) - why (reasons) - how to correct" and "bad habit 2 walking after meals - why (reasons) - how to correct".

\section{Details Repetition}

The teaching procedures: play the recording first and then ask questions. On the basis of students' mastering the main idea, the important details of the original text are asked, so that students can have a certain grasp of the text from the whole and part.

\section{Proper Nouns and Numbers}

For proper nouns and numbers, intensive training in this area is adopted, which are shadow reading, first two numbers and unit memory, slide presentation method.

\section{EXPERIMENTAL STUDY}

\section{A. Research Subjects}

The subjects of this study are students of Translation Class 2018 (control group) and students of Translation Class 2019 (experimental group) in School of Foreign Languages of Zunyi Medical University. The students of these two grades are trained in interpreting for the first time, that is, with no basis.

\section{B. Principles}

In consecutive interpretation, the construction of short-term memory training model must be carried out within the objectives of interpreting teaching (that is, skills-teaching centered), and the corresponding methods and principles 
should be formulated under this goal.

\section{Research Tools}

Spss software was used to analyze the data of students' retelling task.

\section{Experiment Implementation}

\section{Task Design}

In the experimental class (Translation Class 2019), the task-based teaching method of Willis (1996) was used to complete three tasks of memory in interpretation.

1) Pre-task: the teacher introduces the background materials related to the memory task by asking questions to warm up the students;

2) Task cycle: a. Task. Teacher plays a recording of a memory task or presents a memory task material in the class; b. Planning. Students concentrate on listening to the recording or oral presentation, and actively memorize information with their brain; C. Report. Students report the information that they memorize with their brain to the whole class in the form of source language or target language retelling;

3) Post-task: a. Analysis. Some students make self-analysis of difficulties in the process of memorizing, and other students comment on the completion of students' memory tasks, and then teacher comments on the completion of students' memory tasks, so as to emphasize the methods and key points of memory in interpretation; b. Practice. Teacher can provide more practice materials for the objectives of memory training of this course, so as to make the students fully understand the method.

4) Follow-up activities (network teaching auxiliary platform): a. Some students are required to find the similar short-term memory training materials used by teachers in class, search and organize a section of memory materials, and upload them to the network platform; b. Other students use the memory training resource database on the network platform to form a learning group of two. They take turns to play the roles of discourse publisher and memory trainee to carry out autonomous training.

\section{Teaching Arrangement}

The experiment lasts for 6 weeks, two periods a week. See the table below for details.

TABLE 2

TEACHING PLAN

\begin{tabular}{|l|l|l|l|}
\hline $\begin{array}{l}\text { Teaching } \\
\text { Week }\end{array}$ & Teaching Content & Teaching Objectives & Teaching Materials \\
\hline 1 & $\begin{array}{l}\text { Theory of memory in } \\
\text { interpretation and the theory of } \\
\text { discourse type in interpretation }\end{array}$ & Master the two theories & $\begin{array}{l}\text { Theory of memory in interpretation } \\
\text { textbook and supplementary materials) } \\
\text { and discourse type in interpretation } \\
\text { theory and several examples) }\end{array}$ \\
\hline $2-3$ & $\begin{array}{l}\text { Mind drawing } \\
\text { Film projection } \\
\text { Mind drawing plus hand index }\end{array}$ & $\begin{array}{l}\text { Master the method of image } \\
\text { memory in narrative and } \\
\text { descriptive discourse }\end{array}$ & $\begin{array}{l}\text { Challenging Interpreting: } \\
\text { Coursebook of Interpreting Skills, } \\
\text { Yang Liuyan; Basics of Interpreting } \\
\text { Skills, Deng Yi; online resources }\end{array}$ \\
\hline $4-5$ & $\begin{array}{l}\text { Gist extracting and summarizing } \\
\text { Information layered } \\
\text { Details repetition }\end{array}$ & $\begin{array}{l}\text { Master the method of logical } \\
\text { memory in argumentative } \\
\text { discourse }\end{array}$ & $\begin{array}{l}\text { Challenging } \\
\text { Coursebook of Interpreting Skills, } \\
\text { Yang Liuyan; Basics of Interpreting } \\
\text { Skills, Deng Yi; online resources }\end{array}$ \\
\hline 6 & Proper nouns and numbers & $\begin{array}{l}\text { Master the methods of } \\
\text { phonetic memory and picture } \\
\text { memory }\end{array}$ & $\begin{array}{l}\text { Discourse with more proper nouns and } \\
\text { numbers }\end{array}$ \\
\hline
\end{tabular}

\section{Testing}

The retelling parts in the oral test of the 2010 (pre-test) and 2013 (post-test) TEM-4 (Test for English Majors-4) were selected in the experiment. Due to the consistency in difficulty of the oral part in the national standardized test, it won't cause obstacles to students' basic listening comprehension, so as to eliminate the early interference factor. In the test, students were asked to listen to the original text twice and then retell it. We used the recording function of the simultaneous interpretation room to record the whole process of the corpus. 9 students in the experimental group participated in the test. Due to the equipment problems, the effective recording collection rate was $88.9 \%$; 9 students in the control group participated in the test, and the effective recording rate was $88.9 \%$.

After collecting the audio materials, we adopted the scoring standard of the retelling part in the TEM-4 oral test to score the completeness of students' retelling. After that, all the scores were input into SPSS for analysis. The statistical methods involved were single sample t-test and paired sample t-test.

\section{Questionnaire Survey}

After the end of the test, we immediately conducted a questionnaire survey on the 9 students in the experimental group, distributing 9 questionnaires, and collecting 9, with an effective collecting rate of $100 \%$. The questionnaire is 
divided into two parts: the first part is the basic information of the respondents; the second part is the main part, with 18 problems divided into three categories. The first is to ask the difficulty of the test, a total of 13 questions, for yes or no multiple-choice questions: the purpose of setting this kind of questions is to investigate whether the respondents have problems in understanding the test materials, and whether it affects the memory of the test materials. The second is about the effect of memory learning in interpretation. There are two single choice questions, each with the same four options, asking the respondents about the amount of recalling information before and after learning: this group of questions is set up to investigate the learning effect and assist the score data of the experimental group before and after the test. The third is about the effectiveness of training elements (including teachers, methods and materials), with a total of 6 questions.

\section{E. Experimental Results}

\section{Test Results}

According to the comprehensive research methods of the control group and the experimental group, such as pre-test and post test results (effective recording data), questionnaire survey and so on, the experimental results are as follows:

TABLE 3

COMPARISON OF PRE-TEST RESULTS BETWEEN EXPERIMENTAL GROUP AND CONTROL GROUP (SINGLE SAMPLE T-TEST)

\begin{tabular}{|l|l|l|l|l|l|l|l|l|l|}
\hline \multicolumn{2}{|l|}{ Experimental group } & \multicolumn{2}{l}{ Control group } & T value & P value \\
\hline $\begin{array}{l}\text { Maxim } \\
\text { um }\end{array}$ & $\begin{array}{l}\text { minim } \\
\text { um }\end{array}$ & average & $\begin{array}{l}\text { standard } \\
\text { deviation }\end{array}$ & $\begin{array}{l}\text { Maxim } \\
\text { um }\end{array}$ & $\begin{array}{l}\text { minim } \\
\text { um }\end{array}$ & average & $\begin{array}{l}\text { standard } \\
\text { deviation }\end{array}$ & \\
\hline 79 & 73 & 76.25 & 2.121 & 78 & 72 & 74.5 & 2.33 & 1.172 & 0.128 \\
\hline
\end{tabular}

According to the results before the teaching reform (Table 3), the average score of the experimental group was slightly higher than that of the control group, but in view of $\mathrm{T}=1.172, \mathrm{P}=0.128(\mathrm{P}>0.05)$, there was no significant difference between the two groups.

After six weeks of memory training, the average score of the experimental group was 7.25 points, higher than that of the control group, showing a significant level of 0.01 : $\mathrm{T}=4.408, \mathrm{P}=0.003(\mathrm{P}<0.05)$ (Table 4), that is, there was a significant difference in the retelling ability between the experimental group and the control group after the teaching reform, and the retelling ability of the experimental group was significantly improved.

TABLE 4

COMPARISON OF POST-TEST RESULTS BETWEEN EXPERIMENTAL GROUP AND CONTROL GROUP (SINGLE SAMPLE T-TEST)

\begin{tabular}{|l|l|l|l|l|l|l|l|l|l|}
\hline \multicolumn{2}{|l|}{ Experimental group } & \multicolumn{2}{l|}{ Control group } & T value & P value \\
\cline { 1 - 2 } & $\begin{array}{l}\text { Maxim } \\
\text { um }\end{array}$ & average & $\begin{array}{l}\text { standard } \\
\text { deviation }\end{array}$ & $\begin{array}{l}\text { Maxim } \\
\text { um }\end{array}$ & $\begin{array}{l}\text { minim } \\
\text { um }\end{array}$ & average & $\begin{array}{l}\text { standard } \\
\text { deviation }\end{array}$ & \\
\hline 90 & 78 & 83 & 3.742 & 80 & 72 & 75.75 & 2.712 & 4.408 & 0.003 \\
\hline
\end{tabular}

TABLE 5

COMPARISON OF PRE-TEST AND POST-TEST RESUlts OF EXPERIMENTAL Group (PAIRED SAMPLE T- TEST)

\begin{tabular}{|l|l|l|l|l|l|l|l|l|l|}
\hline Pre-test & \multicolumn{2}{l|}{ Post-test value } & P value \\
\cline { 1 - 1 } $\begin{array}{l}\text { Maxim } \\
\text { um }\end{array}$ & $\begin{array}{l}\text { minim } \\
\text { um }\end{array}$ & average & $\begin{array}{l}\text { standard } \\
\text { deviation }\end{array}$ & $\begin{array}{l}\text { Maxim } \\
\text { um }\end{array}$ & $\begin{array}{l}\text { minim } \\
\text { um }\end{array}$ & average & $\begin{array}{l}\text { standard } \\
\text { deviation }\end{array}$ & \\
\hline 79 & 73 & 76.25 & 2.121 & 90 & 78 & 83 & 3.742 & -5.974 & 0.001 \\
\hline
\end{tabular}

Compared with the results of pre-test and post-test in the experimental group (Table 5), there is a significant difference in the data: $\mathrm{T}=-5.974, \mathrm{P}=0.001(\mathrm{P}<0.05)$, and the average score of post-test is 6.75 higher than that of pre-test, which shows that the short-term memory training carried out in the experimental group is effective.

\section{Questionnaire Results}

The effect of short-term memory training is also verified in the questionnaire survey results. The questionnaire investigates the changes of information that students can recall when they only listen to the original text twice without taking notes. The statistical results are shown in Table 6. It can be seen from table 6 that the information recall of the experimental group is more complete and has been greatly improved. Before the experiment, no students could remember it all at once without taking notes

Most of the students $(44.44 \%)$ could only remember one clause / phrase. After the experiment, $55.56 \%$ of the students can remember 2-3 sentences at a time without notes, and $22.22 \%$ of the students can remember a small paragraph (5-7 sentences), so it is greatly improved than it was before the experiment.

TABLE 6

COMPARISON OF INFORMATION RECALL BEFORE AND AFTER THE EXPERIMENT IN THE EXPERIMENTAL GROUP

\begin{tabular}{|l|l|l|}
\hline Information recall & Before the experiment & After the experiment \\
\hline A clause / phrase & $44.44 \%$ & $11.11 \%$ \\
\hline in a word & $22.22 \%$ & $11.11 \%$ \\
\hline 2-3Sentence & $33.33 \%$ & $55.56 \%$ \\
\hline A paragraph (5-7 sentences) & 0 & $22.22 \%$ \\
\hline
\end{tabular}


In addition, the role of teacher, short-term memory training methods and the effectiveness of training materials were also investigated in the questionnaire.

TABLE 7

EFFECTIVENESS OF TEACHER'S ROLE

\begin{tabular}{|l|l|}
\hline The role of teachers & Recognition \\
\hline Short term memory training theory & $88.89 \%$ \\
\hline Training methods of short-term memory & $100 \%$ \\
\hline The selection of targeted exercise materials & $88.89 \%$ \\
\hline Regularly evaluate short term memory practice (including homework review) & $88.89 \%$ \\
\hline
\end{tabular}

According to the survey results in Table 7, students agree with the teacher's role in teaching method, material selection and student evaluation. In particular, it is worth noting that the students' recognition of the effectiveness of the teacher's memory training method reached $100 \%$ (Table 7). The survey also showed that the students' recognition of the effectiveness of memory training materials was $88.89 \%$. Students also need teachers to constantly supervise and evaluate in the learning process $(88.89 \%)$. The class hours of interpretation are very limited, so the teacher must make use of the students' after-class time in the form of homework and spot check in class. In the experimental stage, we made full use of the network platform of the course (Chaoxing Platform), assign homework to students every week, and ask them to upload it within the given time and the teacher checked it in the next class. In class, even if only a small number of students' homework is checked, it can also play a role of comprehensive supervision.

TABLE 8

EFFECTIVENESS OF SHORT-TERM MEMORY TRAINING METHODS

\begin{tabular}{|l|l|}
\hline Training methods & Recognition \\
\hline Summarize the main idea of the original text & $88.89 \%$ \\
\hline Analyze of the original text layer & $66.67 \%$ \\
\hline Answer the important details of the original text & $66.67 \%$ \\
\hline Retell the original text & $88.89 \%$ \\
\hline
\end{tabular}

In terms of the memory training methods, $88.89 \%$ of the students think that "summarizing the main idea of the original text" is effective, and $66.67 \%$ of the students think that "analyzing the level of the original text" is effective (Table 8). To complete the analysis of the original text layer, students need to pay more cognitive efforts. They must grasp the logic of the original text, not just by understanding the main idea. Generally speaking, students have to go from "what to say" to "how to say" to complete the layers division, which is like drawing a mind map in their mind. $66.67 \%$ of the students thought that "answering the important details of the original text" is effective. It is true that memorizing information does not only refer to grasp some details, but also connect it to form a completed meaning. If students can only grasp individual details and can't use logic to connect them, they will eventually be overwhelmed. In addition, $88.89 \%$ of the students think that "retelling the original text" is effective, which indicates that the students recognize the "retelling exercise".

TABLE 9

EFFECTIVENESS OF TRAINING MATERIALS

\begin{tabular}{|l|l|}
\hline Training materials & Recognition \\
\hline Choose image memory and narrative discourse memory & $66.67 \%$ \\
\hline $\begin{array}{l}\text { Choose the texts with a variety of logical relations (cause and effect, } \\
\text { comparison, examples, etc.) to illustrate and discuss discourse memory }\end{array}$ & $88.89 \%$ \\
\hline $\begin{array}{l}\text { Choose materials containing numbers and proper nouns to enhance the memory } \\
\text { of important details }\end{array}$ & $66.67 \%$ \\
\hline Choose materials with no obvious structure to deepen logical memory & $66.67 \%$ \\
\hline
\end{tabular}

With regard to training materials, the students fully affirm "Choose a variety of logical relations (cause and effect, comparison, examples, etc.) to illustrate and discuss discourse memory", and $88.89 \%$ of the students think it is effective (Table 9). The other three items are $66.67 \%$. The reason why we choose materials with less obvious logical structure is that the real interpretation text often has no clear logical relationship, or even logical confusion. This requires interpreters to use logical thinking to "edit and memorize" the source language in order to produce a clear interpretation. However, the students' low recognition of the effectiveness of these materials may be related to their interpretation level: the students we investigated are still in the primary stage of interpretation learning, and they may not have enough ability to accept the challenge of more difficult materials. In the experiment, students are sometimes asked to speak freely, and then other students are asked to memorize or interpret. When the speech is clear, the students can better complete the task of memory and interpretation. However, when the logic of the speech is confused, the students' performance of the task is poor. This shows that in the primary stage of interpreting learning, students' logical memory ability and information processing ability are still limited.

\section{RESULTS ANALYSIS}

Through the analysis of the experimental results, we can find that: 1) the post-test scores of the experimental group 
are significantly higher than the pre-test scores; 2) The amount of information of the experimental group was dramatically improved in the experiment. This shows that the experiment of the short-term memory training is effective. The questionnaire survey on the effectiveness of training elements shows that: 1) Students agree with the teacher's role in teaching methods, material selection and student evaluation; 2) In terms of training methods, students think that the most effective methods are "summarizing the main idea of the original text" and "retelling the original text"; 3) As for training materials, the material with the highest degree of students' recognition is the " texts with a variety of logical relations", which shows that the experiment of constructing short-term memory training based on the theory of discourse type in interpretation is effective.

\section{SUMMARY}

Although the test scores of the experimental group is the most improved, which indicates that the experiment is effective, the questionnaire survey shows that different methods have great differences in effectiveness. Specifically, we should design exercises that can help students carry out high-level information processing and gist extraction activities, improve the understanding of discourse information, and then strengthen the efficiency of information storage and recall. Firstly, the target of interpretation is "meaning" rather than "language". In the experiment, the method of "answering important details" failed to make the students break away from the language form, and did not achieve ideal experimental results. Secondly, Jones (2000) reminds the interpreter not to pay attention to individual words, but to analyze the whole meaning of the text, which requires to identify the definition of the words and the establishment of the meaning connection between the concepts. It can be seen that the logical exercises such as "summarizing the main idea of the original text" and "retelling the original text" exercise the students' ability to grasp the macro meaning of the text and the logical relationship within the text, and achieve good experimental results. Therefore, in the primary stage, we should reduce the difficulty of listening, choose the appropriate discourse type, allocate more energy to memory, and try to have a definite aim in the process of practice, so as to improve students' abilities in this area.

\section{REFERENCES}

[1] Baddeley, A. D. (2000). The Episodic Buffer: A new component of working memory?. Trends in Cognitive Sciences, 4, 417-425.

[2] Bao Gang. (1998). Introducing Interpreting Studies. Beijing: Tourism Education Press.

[3] Bao Xiaoying. (2005). The realization of "faithfulness" - the application of memory psychology in interpretation. Journal of Guangdong University of Foreign Studies, 02, 10-13.

[4] Deng Lin. (2019). The study of memory mechanism in consecutive interpretation. Journal of Kaifeng Institute of Education, 08, 67-68.

[5] Deng Yi \& Liu Ying. (2016). Basics of Interpreting Skills. Shanghai: Shanghai Foreign Language Education Press.

[6] Jones, R. (2000). Conference Interpreting Explained. Shanghai: Shanghai Foreign Language Education Press.

[7] Lei Tianfang \& Chen Jing. (2006). Challenging Interpreting: A Coursebook of Interpreting Skills. Shanghai: Shanghai Foreign Language Education Press.

[8] Li Fangqin. (1999). Interpreting teaching from the perspective of interpreting characteristics. Journal of Sichuan University of Foreign Languages, 03, 77-80.

[9] Li Fangqin. (2004). On memory strategies in interpretation. China Science and Technology Translation, 04, 17-20.

[10] Li Yueran. (1987). On the social function of interpretation. Foreign Language Teaching, 03, 97-98.

[11] Liu Shaolong \& Zhong Weihe. (2008). A neuropsychological study of interpretation: the construction of "process" model in consecutive interpretation. Journal of Foreign Languages (Journal of Shanghai International Studies University), 04, 86-91.

[12] Miller, G. (1956). The magical number seven, plus or minus two: Some limits on our capacity for processing information. The Psychological Review, 63, 81-97.

[13] Ren Wen. (2011). A Coursebook of Interpreting Between English and Chinese. Beijing: Foreign Language Teaching and Research Press.

[14] Su Wei \& Deng Yi. (2009). Basics of Interpreting Skills. Shanghai: Shanghai Foreign Language Education Press.

[15] Wu Cai. (2017). On the strategies to improve short-term memory in consecutive interpretation. Journal of Three Gorges University (Humanities and Social Sciences), S2, $134+141$.

[16] Zhong Weihe. (2003). Interpreter's knowledge structure and interpretation curriculum. Chinese Translators Journal, 04, 65-67.

[17] Zhong Weihe \& Wang Binhua. (2009). A Foundation Coursebook of Interpreting. Beijing: Foreign Language Teaching and Research Press.

Jixin Huang was born in Zunyi City, Guizhou Province, China in 1987. She got a Bachelor's degree in English in 2011, a Master's degree in Translation in 2014 from Guizhou University. She is currently a doctoral student in the School of Humanities, Universiti Sains Malaysia, Penang, Malaysia. Her research interest lies in the teaching and practice of translation and interpretation. 